\title{
POLÍTICAS PÚBLICAS: PANORAMA TEÓRICO E A QUESTÃO DA VIOLÊNCIA CONTRA A MULHER
}

\author{
Augusto Junior Clemente ${ }^{1}$ \\ Carla Mario Brites ${ }^{2}$ \\ Iris Nabolotnyj Martinez ${ }^{3}$
}

RESUMO: Esse estudo visa apresentar as principais abordagens das políticas públicas, privilegiando cinco pontos: (i) o que é uma política pública, (ii) introdução a teoria das políticas públicas, (iii) tipos e modelos de políticas públicas, (iv) atores e instituições no processo de formulação e (v) o ciclo de políticas públicas discutido através das políticas de atenção à violência contra mulher. Objetivamos com essa pesquisa de cunho bibliográfico apresentar didaticamente as principais teorias e conceitos sobre políticas públicas e correlacioná-la com a temática da violência contra a mulher.

Palavras-chave: Política Pública. Teoria das Políticas públicas. Violência contra a Mulher.

\footnotetext{
1 Professor do curso de Administração Pública na Universidade Federal do Paraná - Setor Litoral. Pesquisa sobre Teoria Política, Análise de Redes e Políticas Públicas. E-mail: augustoclemente@ufpr. br.

2 Mestranda do Programa de Pós -Graduação em Políticas Públicas na Universidade Federal do Pampa, campus São Borja. Pesquisa sobre Políticas Públicas, Violência contra a Mulher. E-mail:camabri@gmail.com. 


\section{Z GESTUS SETOR LITORAL}

\section{INTRODUÇÃO}

Este texto trata de uma revisão bibliográfica sobre o estado da arte do tema das políticas públicas, apresentando as principais abordagens das teorias vigentes e correlacionando a teoria do ciclo de políticas públicas à temática da violência contra a mulher. O objetivo desta manobra intelectual é melhor elucidar esse modelo analítico junto às investigações que se debruçam sobre a violência contra as mulheres. Buscase atender cinco pontos que incorporam: (i) o que é uma política pública, (ii) introdução a teoria das políticas públicas, (iii) tipos e modelos de políticas públicas, (iv) atores e instituições no processo de formulação, (v) o ciclo das políticas públicas e a violência contra a mulher.

Entende-se o conceito de política pública como multidisciplinar, dinâmico, abrangente, global e polissêmico, que precisa ser compreendido didaticamente em suas especificidades para uma maior objetividade, clareza e discernimento. Assim, elegemos a violência contra a mulher como um importante tema a ser analisado e correlacionado com a abordagem teórica do ciclo de políticas públicas.

Desse modo, divide-se o trabalho levando em conta os cinco capítulos atrelados aos seus principais autores: no primeiro momento, discute-se a abordagem promovida por Souza (2006-2007) sobre o que é uma política pública, contextualizando a disciplina; no segundo, Saravia (2006) e Ruas (1997) esboçam a introdução à teoria das políticas públicas recomendando autores iniciais; em seguida, os tipos e modelos de políticas públicas são explanados por Dye (2006) e Frey (2000); no quarto momento, Subirats (1989) e Ham e Hill (2007) reconhecem quem são os atores e as instituições que instauram o processo de formulação das políticas públicas; no quinto, discutese o ciclo de políticas públicas de Charles Lindblon (1959) juntamente à temática da violência contra a mulher, identificando-se o processo em que essa problemática torna-se uma reconhecida violação aos direitos humanos, suscitando a necessidade de políticas públicas que a confronte.

\section{O QUE É POLÍTICA PÚBLICA?}

Souza (2006, p.20) busca compreender "como e por que surgiu a área de políticas públicas?" a partir do campo de conhecimento das teorias neoinstitucionalista e de análise. Seu objetivo é fazer uma relação entre as teorias apresentando os principais conceitos, modelos analíticos e tipologias específicas desta área, bem 


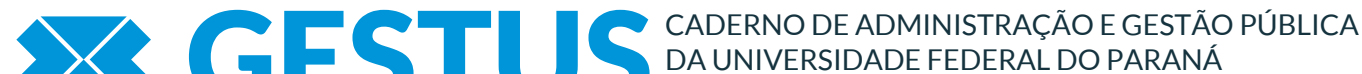 \\ SETOR LITORAL}

como discutindo as possibilidades da aplicabilidade neoinstitucionalista a análise das políticas públicas.

Inicialmente, Souza (2006) contextualiza historicamente a política pública como disciplina acadêmica, demonstrando que ela se deu como subárea da Ciência Política e que surgiu em um contexto norte-americano focando estudos sobre a ação dos governos. Este pressuposto analítico, em democracias estáveis, pôde ser formulado cientificamente e analisado por pesquisadores independentes através das tradições de pensamento que trouxeram às políticas públicas uma nova preocupação em "como e porque os governos optam por determinadas ações" (SOUZA, 2006, p.22). Os autores que incorporaram orientações foram Madison, Paine e Tocqueville. Esta corrente de pensamento deu o pontapé inicial ao que surgiria a seguir sobre as políticas públicas.

Após suas contribuições, os considerados quatro "pais" das políticas públicas, trazem articulações teóricas mais especificas: H. Laswell traz a concepção de policy analysis (análise política) na relação cientistas sociais, grupos de interesse e governo; $\mathrm{H}$. Simon demonstra o conceito de racionalidade limitada dos decisores públicos, policy makers; C. Lindblom faz um contraponto a Laswell e Simon e propõe a inserção de outras variáveis à formulação e análise, como o papel das eleições, das burocracias, dos partidos e dos grupos de interesse; e D. Easton que entende a política pública como um sistema que se dá a partir de entradas (inputs) dos partidos, da mídia e dos grupos de interesse, que influenciam seus resultados e efeitos.

No entanto, para Souza (2006, p.24), apesar de não existir "uma única, nem melhor, definição sobre o que seja política pública" ela identifica sobre os paradigmas mais atuantes de Mead, Lynn, Peters, Dye, e Laswell, que, o deste último, mais reverberou precisamente no ponto em que defende que as decisões e análises sobre política pública respondem a questões de "quem ganha o que, por quê e que diferença faz".

Diante das diversas definições de políticas públicas já citadas pela autora, Souza (2006) refere que o seu campo é holístico e multidisciplinar. Seus diversos olhares correspondem em projetos e pesquisas que contribuem para toda a sociedade de modo amplo, abrangendo várias áreas do conhecimento. Em contrapartida, há que se reconhecer o papel dos governos, os modelos de formulação e de análise e o papel das instituições e regras a decisão e formulação.

Sobre o papel dos governos, Souza (2006) reitera que é aí o centro das decisões às políticas públicas, porém, em sua concepção, o governo não é o maior protagonista, devido ao espaço dos atores que participam do processo decisório. 


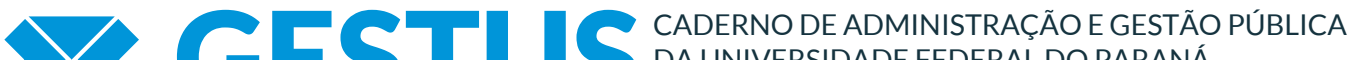 DA UNIVERSIDADE FEDERAL DO PARANÁ SETOR LITORAL}

Pluralismo, estruturalismo e funcionalismo explicam de formas distintas a sua incorporação.

Já os modelos de formulação e análise de políticas públicas demonstram elementos que distinguem o que um governo pretende fazer e o que, de fato, ele faz. Isto pode se dar de várias formas: envolvendo vários atores e níveis de decisão que são materializadas pelos governos, mas não se restringe a eles, abrangendo e não se limitando a leis e regras, demonstrando ser uma ação intencional, com objetivos a serem alcançados, que tem impactos no curto prazo, mas é uma política de longo prazo, e que envolve processos subsequentes após sua decisão e proposição, ou seja, pela implementação, execução e avaliação (SOUZA, 2006).

Sobre o papel das instituições/regras na decisão e formulação de políticas públicas, o debate sobre a escolha racional é o que se reitera. O chamado neoinstitucionalismo, de Olson e de Arrow, trouxe esclarecimentos sobre como as instituições influenciam o desenho das políticas. A ação racional, dessa maneira, não se restringe nos auto interesses dos atores, mas em moldes históricos e institucionais de regras formais e informais que moldam comportamentos e que abrem o espaço para o jogo de interesses nas negociações, pois a "luta pelo poder e por recursos entre os grupos sociais é o cerne da formulação das políticas públicas" (SOUZA, 2006, p. 39).

Souza (2006) considera que a revisão da literatura neoinstitucionalista e de análise de políticas públicas, apresenta quatro elementos:

[...] a própria política pública, a política (politics), a sociedade política (polity) e as instituições onde as políticas públicas são decididas, desenhadas e implementadas. Disso pode-se concluir que o principal foco analítico da política pública está na identificação do tipo de problema que a política pública visa corrigir, na chegada desse problema ao sistema político (politics) e à sociedade política (polity), e nas instituições/regras que irão modelar a decisão e a implementação da política pública (SOUZA, 2006, p. 40).

Dessa maneira, por meio das explanações iniciais de Souza (2006) pode-se compreender como a definição de política pública surgiu e se estruturou historicamente e conceitualmente. No próximo capítulo será discutida a introdução sobre a teoria das políticas públicas. 


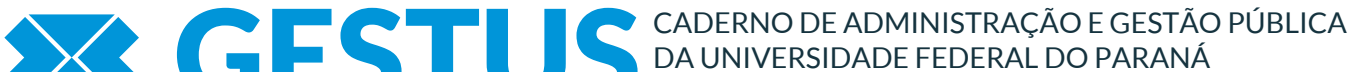 \\ SETOR LITORAL}

\section{INTRODUÇÃO À TEORIA DAS POLÍTICAS PÚBLICAS}

Saravia (2006) e Rua (1997) trazem contribuições sobre o campo teórico das políticas públicas de maneira distintas e é nesse sentido que serão discutidas as perspectivas desses dois autores. O primeiro, apresenta as principais perspectivas teóricas das políticas públicas reconhecendo as vertentes metodológicas jurídicas e das ciências administrativas. A segunda, identifica os conceitos e teorias à análise de políticas públicas, reconhecendo como elas surgem, os principais atores envolvidos, em qual espaço eles estão inseridos, o que buscam e quais as formas de resolução.

Saravia (2006) cita a concepção de administração pública, a partir de um reexame do papel do governo, proposto por Wilson, Barnard e Drucker, identificando mudanças profundas e rápidas do contexto econômico e institucional, vinculados a globalização, que trouxeram à necessidade de competição, a internacionalização de assuntos que eram domésticos, a diversificação das necessidades da sociedade, as novas tecnologias de comunicação e informação, o papel decisivo da mídia, a crescente participação dos usuários, grupos de pressão nos processos decisórios e a transparência e provisão de informação em todas as áreas de ação governamental.

Em decorrência disso, o fortalecimento da ação governamental baseada no planejamento, deslocou-se, a partir da década de 80 , para a ideia de política pública como "um fluxo de decisões públicas, orientado a manter o equilíbrio social ou a introduzir desequilíbrios destinados a modificar essa realidade" (SARAVIA, 2006, p.28).

No entanto, Saravia (2006) afirma que processo de política pública não possui uma racionalidade (previsibilidade) manifesta. Muito pelo contrário, ela é uma dinâmica social e seu o campo de estudo é diversificado e dependerá do ponto de vista do analista. A fim de contribuir para os pesquisadores da área, as políticas públicas podem ser de sete modos: 1) estudos de conteúdos políticos, o analista descreve e explica a gênese e o desenvolvimento de políticas específicas; 2) estudos do processo das políticas, atenção às etapas e se procura verificar a influência de diferentes setores no desenvolvimento desse assunto; 3 ) estudos de produtos de uma política, explica por que os níveis de despesa ou o fornecimento de serviços variam entre áreas; 4) estudos de avaliação se localizam entre a análise de política e as análises para a política e podem ser descritivos ou prescritivos; 5 ) informação para a elaboração de políticas, dados organizados para ajudar os tomadores de decisão a adotar decisões; 6) análise de processo, em que se procura melhorar a natureza dos sistemas de elaboração de políticas; 7 ) análise de políticas, em que o analista pressiona, no processo de política, 


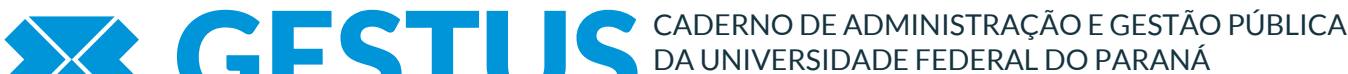 $S_{\text {sropertroest }}$}

em favor de ideias ou opções específicas (SARAVIA, 2006).

Já Rua (1997) se debruça sob outra ótica, ela reconhece que a sociedade heterogênea, diversa e complexa tem como atributo principal o conflito. E resta à política amenizar pacificamente esse conflito por meio de um conjunto de procedimentos, o qual se denomina política pública.

Dessa forma, surgem inputs e withinputs que são as entradas/demandas/ suportes originários dentro do sistema político. A atividade política busca satisfazer as demandas criadas pelos atores sociais ou pelos próprios agentes do sistema político, ao mesmo tempo em que acomodam seus interesses e apoios (RUA, 1997). Essas demandas podem ser novas (de novos atores políticos ou de novos problemas), recorrentes (de problemas resolvidos ou mal resolvidos) e reprimidas (em "estado de coisas" ou de não decisões). Além disso, pode-se distinguir os atores políticos que participam na arena em que os conflitos de interesse estão presentes: atores públicos (população, movimentos sociais, ONGs, empresários, mídia) e atores privados (políticos, burocratas, tecnocratas) (RUA, 1997).

Entretanto, "uma situação pode existir durante muito tempo, incomodando grupos de pessoas e gerando insatisfações sem chegar a mobilizar as autoridades governamentais" (RUA, 1997, p.5): este estado de coisas, explica-se quando algo incomoda um grande número de indivíduos, mas não gera nenhum item na agenda governamental. Por outro lado, um estado de coisas pode vir a se tornar um problema político quando (i) mobilizar ação política, (ii) constituir uma situação de crise e (iii) constituir uma situação de oportunidade. Uma vez que os problemas foram postos é necessário que haja a formulação de alternativas. É nesse momento que os interesses dos atores são postos frente a frente e que se filtram as alternativas (issues: aspecto de uma decisão que afeta o interesse de vários atores e mobiliza expectativas quanto aos resultados da política, catalisando o conflito existente) (RUA, 1997).

Além disso, a dinâmica das relações entre os atores podem ser: de luta, de jogo, de debates e de pressão pública. Entre os vários processos de formulação de alternativas, Rua (1997) filtra três principais: primeiro, o modelo incremental, pequenas decisões rápidas, visa a solução de problemas de maneira gradual, alto potencial de conflito; segundo, modelo racional-compreensivo, grandes decisões lentas, soluções ágeis e rápidas, de grande impacto; e terceiro, o mixed-scanning, misto das duas abordagens, decisões ordinárias e decisões fundamentais. Os dois primeiros apresentam problemas. O terceiro requer que os decisores se engajem em uma visão ampla assim como também uma análise detalhada. Daí se formam as arenas políticas: distributivas (padrão pluralista), regulatórias (padrão pluralista e 


\section{Z GESTUS SETOR LITORAL}

elitista) e redistributivas (padrão do jogo de soma-zero) (RUA, 1997).

Diante do exposto no presente capítulo pode-se vislumbrar introdutoriamente perspectivas sobre a teoria e análise das políticas públicas presentes nas orientações de Saravia (2006) e Rua (1997). Saravia (2006) trouxe as principais perspectivas teóricas das políticas públicas reconhecendo a metodologia das ciências administrativas. Ruas (1997) trouxe os conceitos e teorias de políticas públicas, reconhecendo onde, quem, como, porque e quais as formas de resolução. A seguir abordam-se os tipos e modelos de políticas públicas a partir dos autores Dye (2006) e Frey (2000).

\section{TIPOS E MODELOS DE POLÍTICAS}

Os autores Dye (2006) e Frey (2000), em seus respectivos trabalhos, partem de premissas distintas sobre o mesmo objeto, mas complementam-se sobre os tipos e os modelos das políticas públicas.

Dye (2006) apresenta um levantamento conceitual dos modelos de análise das políticas públicas. Descrevendo que eles são representações físicas ou diagramais que organizam a realidade, identificando modelos conceituais. Sobre a serventia dos modelos apresenta ele apresenta nove tipos: o (1) modelo institucional (foco nas regras); o (2) modelo de processo (foco nas decisões a serem tomadas); o (3) modelo de grupo (foco na interação pelas regras do jogo, pela negociação de acordos, pela oficialização dos acordos, pelo cumprimento efetivo dos acordos; o (4) modelo de elite (foco na dominação de um grupo sobre os demais); (5) modelo racional (foco nos custos e benefícios, este último sempre devem ser maiores. Todos os atores sociais participam e devem conhecer as preferências valorativas e seus pesos, a disponibilidade de políticas, as consequências de cada proposta alternativa, quocientes entre benefício/custo de cada proposta e proposta política mais eficiente,); (6) modelo incremental (foco nas mudanças graduais opõem-se ao modelo racional); (7) modelo da teoria de jogos (foco na escolhas racionais onde dois ou mais participantes estão envolvidos); (8) modelo da opção pública (foco na economia, public choice entende a política como deliberação coletiva de indivíduos movidos pelo auto-interesse); e (9) modelo sistêmico (foco no ambiente condições e circunstâncias externas do sistema político, inputs (entradas), e os outpus (saídas) (DYE, 2006).

Já Frey (2000), além de apresentar semelhante levantamento sobre a análise das políticas públicas, como faz Dye (2006), aborda também o neoinstitucionalismo e 


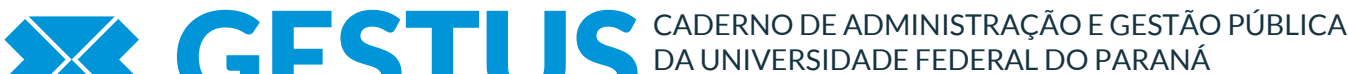 SETOR LITORAL}

a análise dos estilos políticos em contextos de democracia não consolidadas, como o caso brasileiro, apresentando suas peculiaridades.

Desse modo, ele discorre sobre a inter-relação entre instituições políticas (polity), processo político (politics) e conteúdo de política (policy) no contexto proposto. Aprofundando-se nos pilares teóricos fundamentais para a compreensão e estruturação do processo de pesquisa que visa o estudo de casos: (i) policy, (ii) politics, (iii) polity, (iv) policy network, (v) policy arena e (vi) policy cycle - esses conceitos permitem uma integração de distintas abordagens avaliativas em um sistema de referências de caráter processual. Sobre a abordagem neo-institucionalista, Frey (2000, p.231) defende que a problemática das instituições não consolidadas possui um desenho institucional fruto de não somente "um reflexo de necessidades individuais". Esse modelo não explica tudo por meio das instituições, não apresentando maiores explicações nas quais haja processos políticos pouco consolidados, pois o resultado é condicionado de forma subsidiária pelas instituições.

Nesse sentido, um fator explicativo adicional pode ajudar na compreensão: a análise do estilo político. Aqui, há distinção entre padrões de política (atores corporativos, unidades administrativas, partidos e associações) e de comportamento (clientelismo, paternalismo, corrupção) que, ou são peculiares de certos atores, ou transcendem suas ações individuais. As democracias não consolidadas estão em constantes mudanças de padrões, isso influencia os dois objetivos para analisar estilos políticos das políticas públicas em: consolidação de um estilo político empiricamente observado (variável dependente) e um estilo político como primeiro plano (variável independente) (FREY, 2000).

Frey (2000) demonstra que o neoinstitucionalismo e a análise de políticas públicas são abordagens complementares. Mesmo havendo confrontos entre o neoinstitucionalismo e a análise de estilos políticos que colocam seus pressupostos básicos divergentes em afinidades entre as duas propostas, ambas as suas experiências empíricas apontam para condicionalidade mútuas entre as duas dimensões politic e polity.

Frey (2000) defende que a concepção da policy analysis (ou análise política) parece ser a mais apropriada frente à realidade brasileira. No entanto, deve sofrer adaptações às peculiaridades da situação política e institucional do país. Especificamente, deve também reconhecer no conteúdo das políticas (a problemática das questões locais, da transição democrática, das estruturas institucionais) e também dos processos políticos (crises de representatividade, clientelismo, populismo) as mudanças constantes na política material e nos atores políticos envolvidos. Isso 


\section{GESTUS S \\ SETOR LITORAL}

ajuda a compreender o grau da consolidação democrática. Diante disso, Frey (2000, p.251) defende a "integração de elementos de análise de estilos políticos e do neoinstitucionalismo no quadro de policy analysis" como imprescindível para compreender a complexidade e dinâmica dos campos de investigação em questão.

Dessa maneira, neste capítulo percebeu-se que Dye (2006) e Frey (2000) tratam dos tipos e modelos de análise das políticas públicas, no entanto, o primeiro se debruça nos modelos tradicionais, ao passo que o segundo busca uma reinterpretação não somente dos modelos, mas também das abordagens neoinstitucionalista e análise dos estilos políticos proposto frente à realidade das democracias não consolidadas. A seguir serão reconhecidos os atores e instituições no processo de formulação das políticas públicas articulados pelos autores Subirats (1989) e Ham e Hill (2007).

\section{ATORES E INSTITUIÇÕES NO PROCESSO DE FORMULAÇÃO}

Os autores Subirats (1989) Ham e Hill (2007), em seus respectivos trabalhos, apresentam questões sobre atores e instituições no processo de formulação das políticas públicas relacionados a burocracia, aos burocratas e a discricionariedade.

Subirats (1989) discute o papel da burocracia no processo de determinação e implementação das políticas públicas, a partir de cinco pontos: (1) Las burocracias maquinales y el concepto de discreccionalidad; (2) El control de la burocracia; (3) Los recursos de la burocracia y las políticas públicas; (4) Burocracia e implementación; (5) La influencia de la burocracia. Resgatando o caminho da burocracia e demonstrando a importância dos especialistas/burocratas frente à implementação das políticas públicas, discutindo sobre os seus limites.

Ham e Hill (2007) apresentam três pontos sobre as políticas públicas, são eles: (1) A Burocracia e o Estado; (2) Burocratas no Processo de Elaboração de Políticas; (3) Discricionariedade no Processo de Elaboração de Políticas. Os autores defendem que o impacto da burocracia sobre o poder político sugere a importância do papel dos diferentes grupos (incluindo profissões, dentro das organizações) e indica a necessidade de se examinar a forma como as organizações funcionam. As regras e a discricionariedade estão envoltas aos fenômenos sociais, políticos e econômicos que afetam a forma como os burocratas irão proceder frente às políticas propostas.

Deste modo, para analisar como a burocracia interfere nas diferentes etapas das políticas públicas, faz-se necessário, primeiramente, delimitar o que entende-se por "burocracia". A fim de melhor compreender a proposta dos autores, 


\section{Z GESTUS SETOR LITORAL}

utiliza-se do entendimento de burocracia enquanto corpo de funcionários públicos (HAM; HILL, 1993), ou como um conjunto de pessoas organizadas hierarquicamente que realizam um trabalho rotineiro, repetitivo e normatizado, ou seja, "maquinales" (SUBIRATS, 1989).

Nas obras aqui propostas, Ham e Hill (1993) sintetizam as diferentes concepções teóricas acerca do papel das burocracias nas sociedades capitalistas, já Subirats (1989) volta-se para como estas influenciam o processo de formulação e implementação das políticas públicas.

Ao analisar a estrutura burocrática enquanto uma organização "mecânica", Subirats (1989) vincula à teoria weberiana sobre o modelo organizacional burocrático. Conforme Weber, para o trabalho ser realizado de maneira eficiente pela burocracia, as tarefas deverão ser executadas com base nas normativas devendo ter o mínimo de discricionariedade, respeitando os princípios de legalidade e impessoalidade. Subirats (1989) e Ham e Hill (1993) apresentam diversas perspectivas acerca do conceito de discricionariedade, porém elege-se para esta discussão o viés de discricionariedade como a liberdade administrativa e o poder de escolha do burocrata entre alternativas de ação ou não ação nas políticas públicas.

No modo de compreender a burocracia proposto por Weber, Suribats (1989) apresenta que para este a discricionariedade é considerado algo patológico, para ser combatido. Ham e Hill (1993), também discorrendo sobre Weber, afirmam que para o sociólogo o modelo organizacional burocrático seria uma consequência do desenvolvimento de um sistema político e econômico complexo.

Em uma perspectiva oposta, o modelo gerencial de organização da burocracia trata a discricionariedade como necessária para eficácia das políticas públicas. Relaciona-se esta afirmação com a 'burocracia em nível de rua' debatido por Ham e Hill (1993), onde estes utilizam-se da teoria de Lipsky para explicar que as decisões discricionais tomadas pelos burocratas que estão na "linha de frente" formam a política pública que eles executam. Subirats (1989), em consonância com Lipski, apresenta também sobre o alto grau de discricionariedade dos burocratas em nível de rua, o que dificulta o controle sobre a estrutura hierárquica da burocracia.

Desse modo, para os autores a burocracia influência em todas as etapas do ciclo na política pública, porém é na fase de implementação que esta influência fica mais exposta. É nesta etapa que os burocratas transformam a política pública em algo prático, tiram-na "do papel", executam-na. E é neste momento que há maior ou menor discricionariedade. 


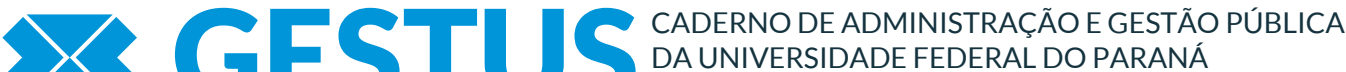 \\ SETOR LITORAL}

Diante disso, nesta seção discorreu-se acerca da burocracia, dos burocratas e da discricionariedade nas políticas públicas a partir das contribuições dos autores Subirats (1989) e Ham e Hill (2007). Na próxima seção, será discutido um método de análise das políticas públicas - ciclo da política pública - entrelaçando seus conceitos à temática da violência contra a mulher, de modo a exemplificar em uma importante temática as fases que as políticas públicas percorrem.

\section{O CICLO DAS POLÍTICAS PÚBLICAS E A VIOLÊNCIA CONTRA AS MULHERES}

A proposta de entendimento de uma política pública foi organizada como um ciclo, chamada por Charles Lindblon (1959) de Ciclo da Política Pública (Policy Cycle), sendo este um importante elemento de análises de políticas públicas (policy analysis). É uma abordagem que possui qualidades destacadas por vários autores que trabalham com o tema e reconhecido como uma ferramenta analítica que contribui para tornar clara e didática sua discussão.

Esse método subdivide em fases parciais o processo político-administrativo de resolução de problemas, revelando-se um modelo bastante interessante para a análise da vida de uma política pública. As tradicionais divisões do ciclo político baseiamse nas fases de: percepção e definição de problemas, "agenda-setting", elaboração de programas e decisão, implementação de políticas e avaliação de políticas (FREY, 2000).

No exercício das políticas públicas esses estágios não são sequenciais ou obrigatórios, sendo comum que se pulem fases ou no meio delas redefinam-se questões importantes para que as políticas públicas sejam eficientes e/ou eficazes. No entanto, sua utilidade enquanto potencial de explicação é atribuída à organização das ideias, à redução da complexidade das políticas e à contribuição na criação de um referencial comparativo entre casos diferentes (SECCHI, 2013).

A Percepção e Definição de Problemas e "agenda-setting" (formação de agenda) é um dos primeiros passos de uma política pública, e por isso, pode ser o mais difícil e importante. Dependendo de como é encarado inicialmente poderá ser determinante na condução das demais fases.

Como já mencionado anteriormente, uma problemática pode existir por um longo tempo na sociedade, sendo pauta de diversos grupos e gerando insatisfações, sem mobilizar as autoridades governamentais, tratando assim de um "estado de coisas". Quando esta problemática passa a preocupar as autoridades torna-se um 


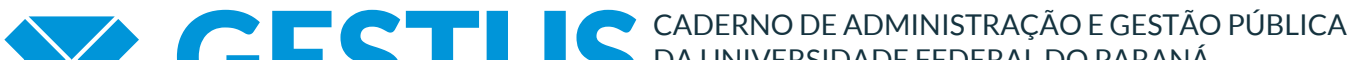 DA UNIVERSIDADE FEDERAL DO PARANÁ SETOR LITORAL}

problema-político e pode passar a fazer parte da agenda governamental (RUA,1997).

Uma das fontes primárias na formação da agenda são as questões sociais, sendo assim a criação da agenda não é um processo lógico-racional e sim um diálogo entre diversos atores interessados no tema em questão. Podemos visualizar esses pontos na temática da violência contra a mulher no Brasil, ao qual teve pouca visibilidade pública por muitos anos, ficando confinada aos espaços domésticos, pelas relações de dominação-subordinação entre homens e mulheres presentes em nossa sociedade.

Porém, esta questão entra no cenário público de discussões e questionamentos a partir da década de 70 , com fortalecimento dos movimentos feministas de mulheres em defesa de seus direitos e mudança das situações de subordinação de gênero, exigindo a criminalização de práticas tradicionalmente toleradas na sociedade, no contexto das relações conjugais.

Rompendo o silêncio que historicamente marca a não inserção das mulheres no debate público, o movimento feminista no final da década de setenta e início da década de oitenta protagonizaram as mobilizações de rua contra a violência machista e as primeiras organizações feministas para receber as denúncias e acolher as mulheres. Lançaram campanhas como "O Silêncio é cúmplice da violência" e "Quem ama não mata" e conseguiram expor com grande repercussão na mídia nacional a questão da violência contra as mulheres, trazendo enorme pressão popular e debate público sobra a problemática. Neste cenário, junto com os grupos sociais e as mulheres, a mídia tornou-se um grupo de pressão de grande alcance e importância para que a violência contra a mulher passasse a fazer parte da agenda de governo.

A focalização de uma questão pela mídia impressa, televisiva e em publicações especializadas pode auxiliar na canalização da atenção de diversos atores participantes das policy communities (CAPELLA,2007).

Após a violência contra a mulher passar de "estado de coisas" para um problema público, entrando na agenda do governo por sua relevância social e cultural, passa-se para o próximo passo do ciclo de políticas públicas, na qual deve centrar-se na elaboração de programas e decisão (formulação de políticas públicas).

O primeiro passo para a formulação da política pública é escolher alternativa possíveis para solucionar o problema. Neste momento o governo considera todas as perspectivas possíveis: política, social, econômica e etc.

O processo político para o surgimento de uma política pública inicia com inputs (demandas sociais) ou withinputs (demanda do próprio sistema político), de forma a 


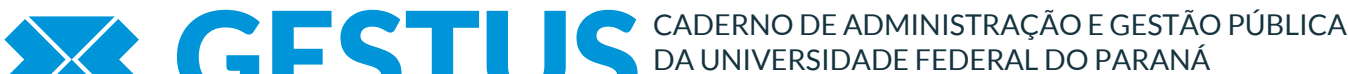 SETOR LITORAL}

acarretar respostas ou outputs (RUA, 2006).

Por se tratar de uma formulação teórica, a fase de formulação pode adentrar na fase de implementação, objetivando uma adaptação à problemas práticos (RONCARATTI, 2008).

O movimento feminista encontrava-se também nessa fase de busca de alternativas para os problemas da violência. Assim, tiveram as primeiras conquistas junto ao Estado em 1985 quando foi inaugurada a primeira Delegacia de Defesa da Mulher e criado o Conselho Nacional dos Direitos da Mulher, com o objetivo de promover políticas sociais para as mulheres, no sentido de eliminar qualquer tipo de discriminação e garantir condições de igualdade para o exercício da cidadania (BRASIL, 2011).

Em 1988 a Constituição Federal Brasileira, em seu artigo 226, dispôs "O Estado assegurará a assistência à família na pessoa de cada um dos que a integram, criando mecanismos para coibir a violência no âmbito de suas relações".

Um dos marcos no que se refere à proteção dos direitos da Mulher, ocorre em 1994, com a realização da Convenção de Belém do Pará, ou Convenção Interamericana para Prevenir, Punir e Erradicar a Violência contra a Mulher. Os Estados membros presentes na Convenção afirmaram que a violência contra a mulher constitui uma violação dos direitos humanos e das liberdades fundamentais. O Brasil ratificou as medidas propostas por estes documentos, comprometendo-se na criação de políticas públicas que tenham por eixo a proteção dos direitos humanos das mulheres e para a erradicação e combate à violência contra a mulher.

A partir deste cenário há a necessidade de planejar, estruturar a máquina pública e provisionar todos os insumos necessários a execução, estando na fase de implementação de políticas públicas.

Esta fase é comentada por Rua (1997) como um conjunto de ações contínuas realizadas por grupos ou indivíduos direcionadas para a consecução de objetivos, fazendo a política sair do papel e funcionar efetivamente. Sendo a implementação um processo interativo e nunca acabado é que as políticas públicas de enfrentamento à violência contra a mulher vem sendo propostas no decorrer dos anos, interagindo com as mudanças e necessidades da sociedade.

Nesse sentido, em 2003 foi lançada a Lei 10.778 que estabelece a notificação compulsória, no território nacional, do caso de violência contra a mulher que for atendida em serviços de saúde públicos ou privados. Têm-se assim, um dos primeiros passos para o mapeamento das formas de violência, dos agentes e das proporções 


\section{Z GESTUS \\ SETOR LITORAL}

dessa problemática.

No ano seguinte, 2004, o Ministério da Saúde, em parceria com diversos setores da sociedade elaborou a "Política Nacional de Atenção Integral a Saúde da Mulher", que define seus princípios norteadores no enfoque de gênero, na integralidade e na promoção da saúde, buscando o combate à violência de gênero/doméstica e sexual. Assim, têm-se como estratégias aumentar o número de serviços de atenção à violência, apoiando-se na organização de redes integradas (BRASIL, 2004).

Outra conquista importante para o enfrentamento da violência contra as mulheres é a Lei Maria da Penha n 11.340/2006 que criou mecanismos para coibir a violência doméstica e familiar contra a mulher (BRASIL, 2006).

Mais recentemente temos o Plano Nacional de Políticas para as Mulheres2013/2015, em consonância com a Política Nacional de Enfrentamento à Violência Contra as Mulheres (2011), este com maior inserção das temáticas de equidade gênero, na luta pela consolidação dos direitos humanos das mulheres em todas suas faces e dimensões e com metas, linhas de ação mais específicas no combate a essa violência (BRASIL,2013).

Alguns outros meios no combate a violência são o "Ligue 180- Central de atendimento à mulher" que serve como canal direto de orientação sobre direitos e serviços públicos para a população feminina em todo o país. Também o Programa "Mulher, Viver sem Violência" que tem o objetivo de integrar e ampliar os serviços públicos existentes voltados às mulheres em situação de violência, mediante a articulação dos atendimentos especializados no âmbito da saúde, da justiça, da segurança pública, da rede sócio assistencial e da promoção da autonomia financeira (BRASIL, 2015).

É preciso considerar o caráter transversal e complexo na implementação de políticas de enfrentamento à violência contra a mulher, pois as ações executadas por diversos órgãos governamentais, dificultando o alcance de metas e objetivos padronizados em todo o Brasil.

Outra dificuldade bastante grande na análise de políticas públicas, última fase do ciclo, é a avaliação de políticas, o que, segundo Roncaratti (2008, p. 42), significa: "o exame objetivo, sistemático empírico dos efeitos da política pública sobre suas metas em termos de objetivos que pretendiam alcançar."

Quando a política pública envolve diferentes níveis de governo, diferentes regiões ou diferentes setores de atividade, pode-se gerar uma problemática na efetiva implementação, tornando o controle do processo muito complexo (RUA, 1997). 
Avaliar as políticas de enfrentamento à violência contra a mulher, em especial, requer uma análise minuciosa e individualizada de cada estado, região ou município brasileiro em suas ações e diretrizes específicas no cumprimento da proposta nacional de trabalho em rede. Segundo a Secretaria de Políticas para as Mulheres essa rede de enfretamento da violência é composta por: agentes governamentais e nãogovernamentais, formuladores, fiscalizadores e executores de políticas voltadas para as mulheres; serviços/programas voltados para a responsabilização dos agressores; universidades; órgãos federais, estaduais e municipais responsáveis pela garantia de direitos e serviços especializados e não-especializados de atendimento às mulheres em situação de violência.

Atualmente, não existe informação concreta sobre o efetivo cumprimento dos objetivos e metas das políticas e ações pactuadas. Esta se dá pela dificuldade da obtenção das mesmas nas cidades brasileiras, pelo pequeno número de estudos específicos sobre a análise das políticas públicas de combate à violência contra a mulher e por se tratar de questões tão complexas que dificilmente documentos dariam conta de retratar a realidade.

De forma geral, existem no país aproximadamente 969 serviços especializados de atendimento às mulheres, dentre os quais: 415 Delegacias da Mulher (DEAMs); 103 núcleos especializados em delegacias comuns; 192 Centros de Referência de Atendimento à Mulher; 71 casas abrigo; 61 juizados especializados de violência doméstica e familiar; 27 varas adaptadas; 64 promotorias especializadas e 36 núcleos ou defensorias especializadas (CPMI,2013).

Houve um grande avanço no reconhecimento e combate à violência contra a mulher, mas a rede de proteção ainda conta com uma pequena quantidade e uma má distribuição de estabelecimentos especializados no país, concentrados em grande parte nas capitais e regiões metropolitanas, revelando a dificuldade de acesso das mulheres que vivem em regiões distantes.

Reconhece-se que estas ferramentas são parte de uma resposta imediata a um problema cuja solução a longo prazo está em mudanças estruturais, culturais e sociais bem mais profundas. No entanto, a efetividade das políticas públicas para as mulheres somente será realizada se houver a institucionalização, nos estados e nos municípios, de instâncias governamentais capazes de realizar essas políticas, visando diminuir as desigualdades entre homens e mulheres e para atender às necessidades específicas desta população. 


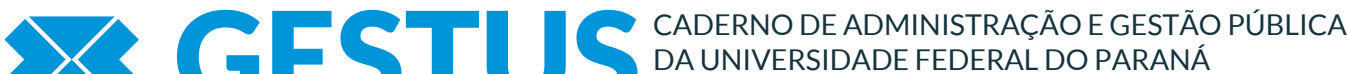 SETOR LITORAL}

\section{CONSIDERAÇÕES FINAIS}

Esse estudo apresentou o estado da arte sobre a teoria das políticas públicas a partir de cinco pontos de principais autores elegidos. No primeiro momento, verificou-se a abordagem promovida por Souza (2006-2007) sobre o que é uma política pública contextualizando inserção da política pública como a disciplina. No segundo, Saravia (2006) e Rua (1997) esboçam a introdução à teoria das políticas públicas recomendando autores iniciais, de abordagens metodológicas distintas. Em seguida, os tipos e modelos de políticas públicas são explanados por Dye (2006) e Frey (2000), em que o primeiro se debruça nos modelos tradicionais, ao passo que o segundo busca uma reinterpretação não somente dos modelos, mas também das abordagens neoinstitucionalista e análise dos estilos políticos proposto frente a realidade das democracias não consolidadas. No quarto momento, Subirats (1989) e Ham e Hill (2007) reconhecem quem são os atores e as instituições que instauram o processo de formulação das políticas públicas.

No quinto e último momento, Lindblon (1959) traz uma importante proposta de entendimento do processo político-administrativo que conformam as políticas públicas, o ciclo das políticas públicas, a qual foi trazida nesse estudo a correlação das suas etapas - percepção e definição de problemas; agendamento (agenda-setting); elaboração de programas e decisão; implementação; avaliação de políticas - com a temática da violência contra a mulher.

Apreende-se desse modo, como o processo de uma política pública, especialmente das políticas de atenção à violência contra a mulher, mostra-se tortuoso, devido aos avanços e retrocessos durante todas as etapas do ciclo da política. Assim, embora no Brasil a violência seja um fenômeno reconhecidamente presente na vida de milhões de mulheres, possuindo hoje diversos mecanismos em diferentes instituições políticas para o enfrentamento dessa problemática, ainda percebe-se retrocessos. Esses são percebidos, por exemplo, quando não existem estatísticas sistemáticas e oficiais que apontem para a magnitude deste fenômeno e ainda na dificuldade do reconhecimento da violência contra as mulheres como uma dimensão de gênero, ou seja, uma construção social, política e cultural.

Importante ressaltar em toda essa dinâmica, atores engajados para que essa trajetória não tenha recuos, como no caso do movimento feminista, corresponsáveis não só pelas inúmeras conquistas apontadas ao longo do tempo, mas também como forma de resistência para que essas continuem sendo efetivadas e aprimoradas. Nesse sentido, visualiza-se o ciclo das políticas públicas de atenção as mulheres em 


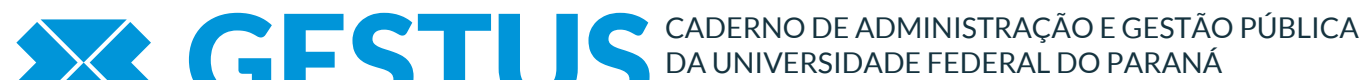 \\ SETOR LITORAL}

situação de violência no Brasil, através de uma linha do tempo, ilustrando apenas alguns marcos importantes no processo da temática da violência contra a mulher:

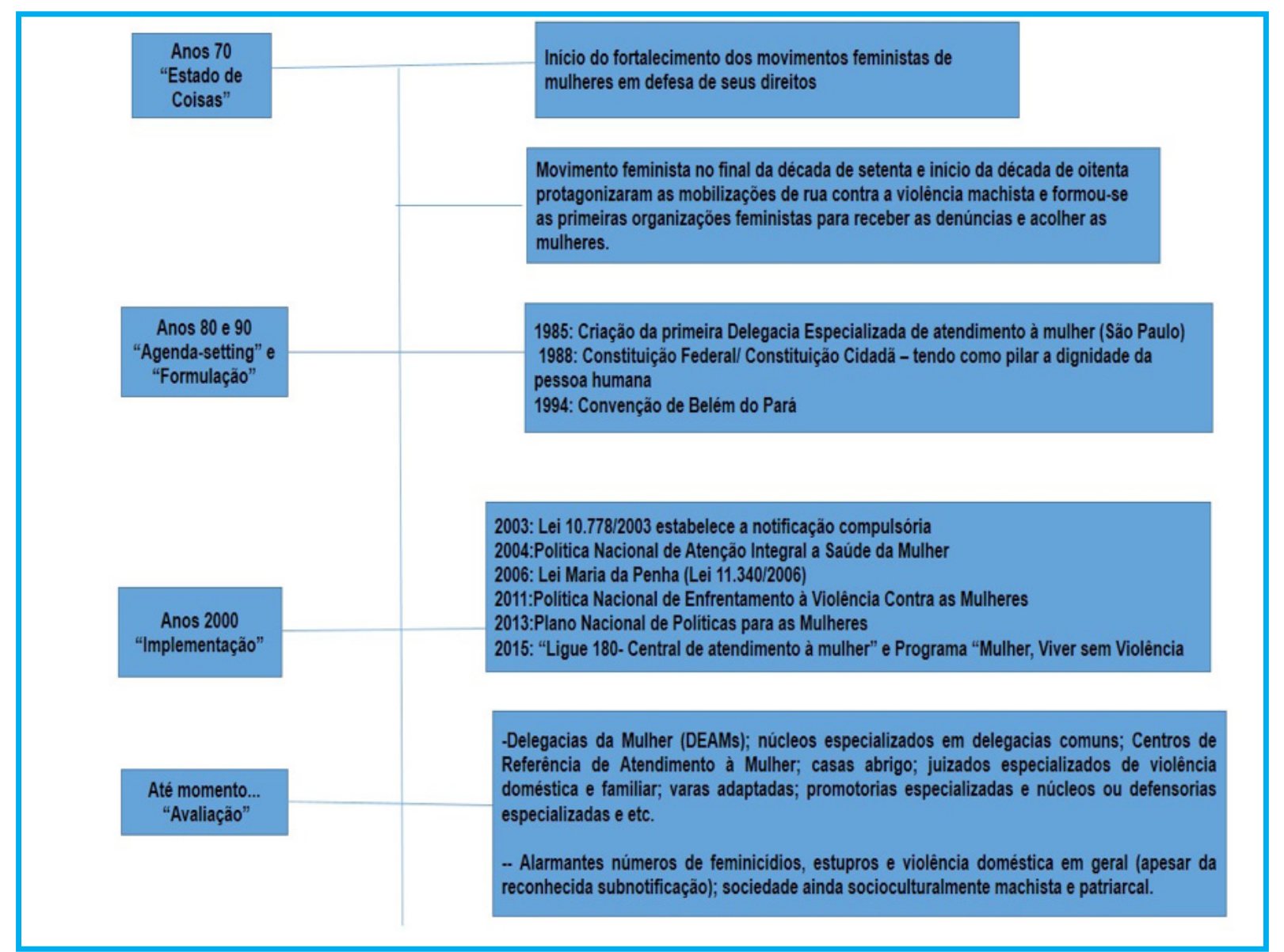

Fonte: Elaborada pelos autores

Em suma, buscou-se discernir cada campo conceitual que incorpora a teoria e análise das políticas públicas levando em conta sua multidisciplinaridade e polissemia. Entretanto, é evidente reconhecer que o pesquisador que deseja se debruçar em perspectivas teóricas das políticas públicas deve tomar cuidado em não confundir epistemologias distintas para não comprometer sua pesquisa com análises equivocadas. Ainda, a partir da breve sistematização do ciclo de políticas públicas de enfrentamento à violência contra a mulher, buscou-se contribuir na problematização das dificuldades de enfrentamento dessa temática. Também, na necessidade de ampliação e garantia dos direitos de cidadania das mulheres e mudança de postura da sociedade frente a esta problemática, com o aumento do empoderamento desta parcela da população. 


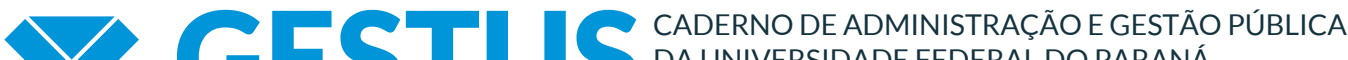 DA UNIVERSIDADE FEDERAL DO PARANÁ SETOR LITORAL}

\section{REFERÊNCIAS}

BAUMGARTNER, Frank R.; JONES, Bryan D.; MORTENSEN, Peter B. Punctuated equilibrium theory: Explaining stability and change in public policymaking. Theories of the policy process, p. 59-103, 2014.

BRASIL. Constituição (1988). Constituição da República Federativa do Brasil. Brasília, DF: Senado Federal: Centro Gráfico, 1988. 292 p.

Ministério da Saúde. Lei n. 10.778 de 24 de novembro de 2003. Estabelece a notificação compulsória, no território nacional, do caso de violência contra a mulher que for atendida em serviços de saúde públicos ou privado. Brasília, 2003.

Ministério da Saúde. Secretaria de Atenção à Saúde. Departamento de Ações Programáticas Estratégicas. Política Nacional de Atenção Integral à Saúde da Mulher: plano de ação 2004-2007 / Ministério da Saúde, Secretaria de Atenção à Saúde, Departamento de Ações Programáticas Estratégicas- Brasília: Ministério da Saúde, 2004.

SECRETARIA ESPECIAL DE POLÍTICAS PARA AS MULHERES, Lei Maria da Penha $\overline{\text { Lei } n^{\circ} 11.340}$ de 07 de agosto de 2006 - Coíbe a violência Doméstica e familiar contra a Mulher. Brasília: 2006.

Presidência da República. Secretaria de Políticas para as Mulheres. Política Nacional de Enfretamento à Violência contra as Mulheres. Brasília: Secretaria Nacional de Enfrentamento à Violência contra as Mulheres,2011.

Presidência da República. Secretaria de Políticas para as Mulheres. Plano Nacional de Políticas para as Mulheres. Brasília: Secretaria de Políticas para as Mulheres, 2013.

Secretaria Especial de Políticas para as Mulheres (SPM). Portal Brasil. Ministério da Justiça e Cidadania. Disponível em: <http://www.spm.gov.br/>. Acessado em: 06 jul.2018.

CAPELLA, Ana Cláudia N. Perspectivas teóricas sobre o processo de formulação de políticas públicas. Políticas Públicas no Brasil. Rio de Janeiro,

Fiocruz, pp. 87-122, 2007.

\section{COMISSÃO PARLAMENTAR MISTA DE INQUÉRITO (CPMI). Senado Federal.}

Secretaria Geral da Mesa. Secretaria de Comissões. Relatório Final. Brasília:

Subsecretaria de Apoio às Comissões Especiais e Parlamentares de Inquérito,2013. Disponível em: $\quad<$ http://www.compromissoeatitude.org.br/wp-content/uploads/2013/06/relatoriofinalcpmi.pdf>. Acessado em: 05 jul.2018.

FREY, Klaus. Políticas públicas: um debate conceitual e reflexões referentes à prática da análise de políticas públicas no Brasil. Planejamento e políticas públicas, n. 21, jun de 2000.

HAM, C. e HILL, M. O processo de elaboração de políticas no Estado capitalista moderno. Campinas, tradução: Renato Amorim e Renato Dagnino, adaptação e revisão: Renato Dagnino.

HEIDEMANN, Francisco G; SALM, José Francisco; GUIMARÃES, Tomás de Aquino. Políticas públicas e desenvolvimento: bases epistemológicas e modelos de análise. Editora UnB, 2006.

LINDBLOM, Charles. E. The Science of "Mudding Though". Public Administration Review. 1959. Vol. 19, No. 2 (Spring, 1959), pp. 79-88. 


\section{$\nabla$ GESTUS $\checkmark(5)$ DA UNIVERSIDADE FEDERAL DO PARANÁ SETOR LITORAL}

MARCH, James. Como as decisões realmente acontecem: princípios da tomada de decisões. São Paulo: Leopardo, 2009.

RUA, M. das Graças (1997). Análise de Políticas Públicas: Conceitos Básicos. Washignton, DC: Indes/BID. Texto digitado. Disponível em: < http://www.clebertoledo.com.br/blogs/gestaopublica/ administracao/files/files/pol_publicaS_Gra\%C3\%A7aRUA.pdf>. Acesso em: 07 jul.2018.

RUA, M. das Graças; AGUIAR, Alessandra. A política industrial no Brasil,1985-1992: políticos, burocratas e interesses organizados no processo de policy-making. In SARAVIA \& FERRAREZI, Políticas Públicas, Enap, 2006.

SARAVIA, E. Introdução à teoria da política pública. In: SARAVIA, Enrique; FERRAREZI, Elisabete. (Orgs.). Políticas públicas, Brasília: ENAP, v. 1, p. 21-42, 2006.

SOUZA, Celina. Políticas públicas: uma revisão da literatura. Sociologias. vol. 8, n. 16, pp. 20-45, 2006.

SECCHI, Leonardo. Políticas Públicas - Conceitos, esquemas de análise, casos práticos, $2^{\mathrm{a}}$ ed. São Paulo: Cengape Learning, 2013.

RONCARATTI, Luanna Sant'Anna. Caderno de Políticas Públicas. Ministério do Planejamento, Orçamento e Gestão. Brasília, 2008. 